\title{
Effects of a Structured Training Plan in Technical-Tactical Exercises on Unforced Errors in Competition in Table Tennis Athletes
}

\section{Juan Camilo Soto Jaramillo*}

Degree in Physical Education and Psychology Student, Universidad de Antioquia, Antioquia, Colombia

*Corresponding Author: Juan Camilo Soto Jaramillo, Degree in Physical Education and Psychology Student, Universidad de Antioquia, Antioquia, Colombia.
Received: August 17, 2021

Published: September 09, 2021

(C) All rights are reserved by Juan Camilo Soto Jaramillo.

\begin{abstract}
Table Tennis is a sport characterized by the high speed of play at which it is practiced, the constant decision-making process that athletes are faced with and the high levels of technical precision that they must possess when developing on a rather small playing surface. If you add to these aspects the fact that the points of tension and the situations that destabilize the athletes are presented in a recurrent way in the competitions, you haven enough arguments to understand why the tennis players make a lot of unforced errors in the matches. The present research exercise was framed in a methodological proposal that generated statistically significant results $(p<0.002)$ on the reduction of unforced errors in competition in a group of table tennis players.
\end{abstract}

Keywords: Table Tennis; Unforced Errors; Performance; Training Plan

\section{Introduction}

Tactical thinking is one of the elements that give greater characterization to the practice of table tennis, since, as mentioned by López (2009) "Table tennis is a sport in which the tactical aspect predominates". The most decisive issue is not the force that is imprinted on the ball, nor the degree of technical perfection with which it is performed, but the most decisive thing is to decide where to place the ball [4].

Generate training plans where a whole methodological process is emphatically included to stimulate the improvement in decisionmaking and therefore the decrease in unforced errors in competition by athletes is a priority issue since, as stated by the sports psychologist Benito Urra during the celebration of the international scientific congress applied to table tennis in 2003 “... table tennis is a continuous decision-making process that subordinates the role of technical purity to the background..." [11] however, decisionmaking is constantly altered in a negative way by intrinsic factors (insecurity, stress, family pressures, etc.) and extrinsic (loneliness in the game or, decisive points, high speed in decision-making in table tennis, etc.) in the athlete; very often the different conditions of play, their speed, their complexity and the "potentially destabilizing situations" that plantea López(2009) generate in tennismesist as negative emotions and these in turn are more likely to make unforced errors when making decisions during competitions [4].

This academic exercise aimed to generate training methods with an investigative basis framed in a training plan that would allow a group of table tennis athletes from Carmen de Viboral, municipality of the department of Antioquia, in the U15, U18 and Senior categories, to form much more efficient decision-making processes that could be reflected in the competitions in a positive way in the moments of the matches in which destabilizing situations are present producing unforced errors.

\section{Methodology}

Design

The present investigative exercise had a quasi-experimental scope, in which we tried to establish the pre- and post-test differences in unforced errors in competition, after the application of a structured training plan to part of technical-tactical exercises that simulated destabilizing game situations and stimulated tactical 
thinking and decision-making to a group of table tennis athletes. Called for this purpose experimental group (G1) with respect to another group with similar characteristics, control group (G0) who continued to develop their regular training plan, which placed greater emphasis on technical issues, however like the G1 were evaluated.

\section{Sample}

A group of 12 tennis players (total population of the group) belonging to the table tennis club of Carmen de Viboral with residence in this municipality with an age range between 14 and 23 years, who had a minimum training experience of 2 years, was selection. The athletes were intentionally selected since they were part of a training group with ideal characteristics to develop research (advanced technical and competitive levels, greater experience in the participation of tournaments, etc.). The Sample was randomly divided through the program "EPIDAT" Version 3.1 into two subgroups, 8 for G1 and 4 for G0.

Since the sample was too small to give a scientific certainty that the results are true, the present and research exercise is determined as a pilot project.

\section{Variables}

Independent variable: Structured training plan in technicaltactical exercises

A training plan is a logical way to structure the stimuli that will be applied to athletes in a certain period of time, seeking to generate higher levels of performance in them and more efficient ways to meet the objectives of the sport. In the development of this research proposal, it will be structured in technical-tactical exercises, which implies that the central point of the plan will be based on proposing exercises that combine technical efficiency with the ability to make decisions and solve problems at the table, and that will be treated as follows: exercises, training load and planning structures.

\section{The exercises}

For this purpose, a battery of exercises coded into 12 task groups, divided into technical, tactical, physical, psychological and theoretical aspects, was created in an Excel document; these exercises were characterised by their nature, type of interconnection, volume and intensity of the load (See table 1).

\begin{tabular}{|c|c|c|c|c|}
\hline \multicolumn{5}{|c|}{ Exercise Group Table } \\
\hline Nature & $\begin{array}{l}\text { Intercon- } \\
\text { nection }\end{array}$ & Volume & $\begin{array}{l}\text { Inten- } \\
\text { sity }\end{array}$ & Task group table \\
\hline General & Positive & 5 & 1 & $\begin{array}{l}\text { 1. Volume exer- } \\
\text { cises. }\end{array}$ \\
\hline Specific & Positive & 5 & 1 & $\begin{array}{l}\text { 2. With short lay- } \\
\text { offs }\end{array}$ \\
\hline Specific & Positive & 4 & 2 & $\begin{array}{l}\text { 3. With long dis- } \\
\text { placements }\end{array}$ \\
\hline Specific & Positive & 4 & 2 & $\begin{array}{l}\text { 4. Shifting combi- } \\
\text { nations. Simple }\end{array}$ \\
\hline Specific & Positive & 3 & 3 & $\begin{array}{l}\text { 5. Scroll combina- } \\
\text { tions. Complexes }\end{array}$ \\
\hline Specific & Positive & 2 & 4 & $\begin{array}{l}\text { 6. With accelera- } \\
\text { tion and auctions }\end{array}$ \\
\hline Specific & Positive & 1 & 5 & $\begin{array}{l}\text { 7. Simulation criti- } \\
\text { cal points }\end{array}$ \\
\hline Specific & Positive & 1 & 5 & 8. Competition \\
\hline General & Refusal & Varies & Varies & $\begin{array}{l}\text { 9. General Physical } \\
\text { Component }\end{array}$ \\
\hline Specific & Positive & Varies & Varies & $\begin{array}{l}\text { 10. Special Physi- } \\
\text { cal Component }\end{array}$ \\
\hline Specific & Positive & Varies & 0 & $\begin{array}{l}\text { 11. Neto Psycho- } \\
\text { logical Component }\end{array}$ \\
\hline General & Positive & Varies & 0 & $\begin{array}{l}\text { 12. Neto Theoreti- } \\
\text { cal Component }\end{array}$ \\
\hline
\end{tabular}

Table 1: Group of general exercises with their respective classification.

Of the exercises created, it is determined that the exercises called: With accelerations and auctions (11 exercises in total), Simulation of critical points (7 exercises in total), Competition (7 exercises in total) as shown in table 2 will be exclusive for the intervention of the experimental group (G1).

\begin{tabular}{|l|c|c|c|c|}
\hline \multicolumn{5}{|c|}{ Exercise Group Table G1 } \\
\hline Nature & $\begin{array}{c}\text { Intercon- } \\
\text { nection }\end{array}$ & Volume & Intensity & Task Group Table \\
\hline Specific & Positive & 2 & 4 & $\begin{array}{c}\text { With acceleration } \\
\text { and auctions }\end{array}$ \\
\hline Specific & Positive & 1 & 5 & $\begin{array}{c}\text { Simulation critical } \\
\text { points }\end{array}$ \\
\hline Specific & Positive & 1 & 5 & Competition \\
\hline
\end{tabular}

Table 2: Group of exercises selected for intervention of the experimental group. 
The training load

For the management of volume and intensity, a table of volume per session is generated in ascending scale from 1 to 5 (being 1 the lowest volume and 5 the highest) guided by the number of total hits for a session of 2 hours, and a table of intensities in descending scale of 5 to 1 (being 5 the highest intensity and 1 the lowest) following the logic of the number of blows per minute according to the complexity of the task based on the advanced training manual of the ITTF, the proposal de tables of volume and intensity that professor Carlos Alberto Agudelo makes in 2016 during the development of the axis of organization of the sports training of the undergraduate degree in physical education of the University of Antioquia and some of the antecedents that characterize the table tennis (See table 3 and 4).

\begin{tabular}{|c|c|}
\hline \multicolumn{2}{|c|}{ Table Volume Session } \\
\hline Volume & $\mathbf{N}^{\circ}$ of Blows \\
\hline 5 & 4000 or more \\
\hline 4 & $3999-3000$ \\
\hline 3 & $2999-2000$ \\
\hline 2 & $1999-1000$ \\
\hline 1 & 999 the least \\
\hline
\end{tabular}

\begin{tabular}{|c|c|}
\hline \multicolumn{2}{|c|}{ Session Intensity Table } \\
\hline Intensity & $\begin{array}{c}\text { Strokes/ } \\
\text { minute }\end{array}$ \\
\hline 1 & 60 or more \\
\hline 2 & $59-50$ \\
\hline 3 & $49-40$ \\
\hline 4 & $39-30$ \\
\hline 5 & $29-$ less \\
\hline
\end{tabular}

Table 4: Load intensity depending on type of exercise.

After the battery of exercises has been created, determine how the volume and intensity of these will be handled and assume that the exercises selected to participate in the G1 will be from the codified task groups: with acceleration and auctions, simulation of critical points and competition; the specific training load for the G1 is generated (See table 5) with a ripple of the weekly load from the simple to the complex and from the general to the most specific that would be the competition. All tasks will have a positive interconnection with respect to technique and actual game situations.

Table 3: Volume for two hours.

\begin{tabular}{|c|c|c|c|c|c|c|c|c|c|c|c|}
\hline \multicolumn{12}{|c|}{ Summary Training Load G1 } \\
\hline \multirow{2}{*}{\multicolumn{2}{|c|}{$\begin{array}{c}\text { Months } \\
\text { Microphones }\end{array}$}} & Feb & \multicolumn{4}{|c|}{ March } & \multicolumn{4}{|c|}{ April } & May \\
\hline & & & 1 & \begin{tabular}{|l|}
2 \\
\end{tabular} & \begin{tabular}{|l|}
3 \\
\end{tabular} & \begin{tabular}{|l|l}
4 \\
\end{tabular} & \begin{tabular}{|l|}
$\mathbf{5}$ \\
\end{tabular} & 6 & 7 & \begin{tabular}{|l|}
8 \\
\end{tabular} & \multirow[b]{2}{*}{$01 / 05 / 17$} \\
\hline \multicolumn{2}{|c|}{ Dates (Micros) } & $27 / 02 / 2017$ & $06 / 03 / 17$ & $13 / 03 / 17$ & $20 / 03 / 17$ & $27 / 03 / 17$ & $03 / 04 / 17$ & $10 / 04 / 17$ & $17 / 04 / 17$ & $24 / 04 / 17$ & \\
\hline \multicolumn{2}{|c|}{ Mesociclos } & & \multicolumn{4}{|c|}{1} & \multicolumn{4}{|c|}{2} & \\
\hline \multicolumn{2}{|c|}{ Test } & $\mathrm{X}$ & & & & & & & & & $\mathbf{X}$ \\
\hline \multicolumn{2}{|c|}{ Micro \# } & 0 & 1 & 2 & 3 & 4 & 5 & 6 & 7 & 8 & 9 \\
\hline \multirow{7}{*}{$\begin{array}{l}\text { Sessions } \mathrm{x} \\
\text { micro }\end{array}$} & The & & Or & Or & Or & Or & Or & Or & Or & Or & \\
\hline & $\mathrm{M}$ & & Or & Or & Or & Or & Or & Or & Or & Or & \\
\hline & In & & Or & Or & Or & Or & Or & Or & Or & Or & \\
\hline & $\mathrm{I}$ & & & & & & & & & & \\
\hline & In & & Or & Or & Or & Or & Or & Or & Or & Or & \\
\hline & $\mathrm{S}$ & & Or & Or & Or & Or & Or & Or & Or & Or & \\
\hline & $\mathrm{D}$ & & Or & Or & Or & Or & Or & Or & Or & Or & \\
\hline \multicolumn{2}{|c|}{ Tasks } & & & & & & & & & & \\
\hline \multirow[t]{2}{*}{$6--1$} & I & & 4 & & & 4 & & & & & \\
\hline & In & & 2 & & & 2 & & & & & \\
\hline \multirow[t]{2}{*}{$6--2$} & I & & 4 & & 4 & & & & & & \\
\hline & In & & 2 & & 2 & & & & & & \\
\hline \multirow[t]{2}{*}{$7--1$} & I & & & & 5 & 5 & & 5 & & 5 & \\
\hline & In & & & & 1 & 1 & & 1 & & 1 & \\
\hline \multirow[t]{2}{*}{$7--2$} & I & & & & 5 & & 5 & 5 & & 5 & \\
\hline & In & & & & 1 & & 1 & 1 & & 1 & \\
\hline \multirow[t]{2}{*}{$8--1$} & I & & & & & & 5 & & & 5 & \\
\hline & In & & & & & & 1 & & & 1 & \\
\hline \multirow[t]{2}{*}{$8--2$} & I & & & & & & & 5 & & & \\
\hline & In & & & & & & & 1 & & & \\
\hline \multicolumn{3}{|c|}{ Total load: } & & & & & & & & & For. Total: \\
\hline \multicolumn{3}{|c|}{ Volume } & 2 & 2 & 2 & 2 & 1 & 1 & 1 & 1 & 2 \\
\hline \multicolumn{3}{|c|}{ Intensity } & 4 & 5 & 4 & 4 & 5 & 5 & 5 & 5 & 5 \\
\hline
\end{tabular}

Table 5: Summary of training load for experimental group, example with some exercises. 
Dependent variable: Unforced errors

Marí (1997) quoted by López (2009), "considers unforced error that is not motivated by the action of the opposite, but by the mistake itself, and that the player by his level does not usually fail" [4]. These errors are recurrently presented by the appearance of fear, anxiety, stress or other emotions that are present in the sports when facing the competitions and that lead the player to make bad technical-tactical decisions and/or to have less precision in the execution of the techniques.

During this investigative exercise the dependent variable had the following trying: a test was carried out prior to the application of the independent variable with a series of technical-tactical exercises that will simulate real actions of competition where there is a tendency to commit unforced errors, this test served to keep a control of the efficiency of the load, in addition to this is make an audio-visual record of a match to 3 of 5 sets in one of the competitions of control of the athletes; as follows.

\section{Test technical-tactical exercises}

This test is a pilot test in which each exercise had 10 attempts of which the number of hits (winning the point) and the number of mistakes (losing the point) were added.

Exercise \#1 third balls: Perform a service and win the point with an offensive action in the next possibility of shot (if the partner does not receive the service will be null attempt and will not count).

Exercise \#2 fifth ball: perform a service, strategically place the ball in the next possibility of shot to later win the point with an offensive action on the next shot (if the partner does not receive the service will be null attempt and will not count).

Exercise \#3 simulation of tie 10 to 10 (lengthen): the player will have a service and the opponent another, it will be a success when the player is the first to win two points in a row, if the opponent is the one who gets it first it will be a mistake. Five times will start serving and 5 receiving.

\section{Test in competition}

In this test a complete match of each player in the sample was recorded, to 3 of 5 sets during the development of the first week of competition on Sunday after the application of the first tests (tacti- cal technician), from the video the data of unforced errors was extracted: direct failure of the service, direct failure of the rest of the shots in good shooting position, not making contact with the ball, failing a high ball without effect, failing third ball (serving and failing the first attack attack), failing the first block, faults of initiative in the points (not attacking in good position and failing). Proposed by López (2009) [4].

Data analysis

Descriptive

After throwing the test data into an Excel table, the IBM SPSS version 22 program was used to calculate measures of central tendency (Mean, Minimum, Maximum and standard deviation) to perform a descriptive statistical analysis both of the way in which the subjects started the study and the way in which they evolved after applying the independent variable (pre-test and post-test changes).

\section{Inferential}

After comparing the pre- and post-test data through the measures of central tendency, an analysis of the possible changes that occurred and the relationship that exists between them and the different variables was performed, for which a Shapiro-Wilk normality test was applied to determine if the groups had a normal statistical behavior, after determining this aspect a Student's t was applied for related samples that allowed a comparison of the means of the variables: technical-tactical test and test in competition.

\section{Hypothesis system}

\section{Research null hypothesis 1 (Ho1)}

There are no statistically significant variations in the unforced errors in competition, once the 8-week training plan, structured from technical-tactics exercises for a group of table tennis players belonging to the table tennis club of Carmen de Viboral, has been completed.

\section{Alternative research hypothesis 1 (HA1)}

There are statistically significant variations in unforced errors in competition, once the 8-week training plan, structured from technical-tactical exercises for a group of table tennis players belonging to the carmen de Viboral table tennis club, has been completed. 


\section{Results}

\section{Technical-tactical test}

When using the inferential statistic, called students 't-test, for comparison of means in the exercises that make up the technicaltactical test, the results were as follows.

As for the correct answers in exercise1, there are no statistically significant changes either for the G1, which has a significance level of 0.31 ( $p \leq 0.05$ ) between the pre and post-test, nor for the G0, which has a significance level of 0.39 , ( $p \leq 0.05)$ between the pre and post-test (See table 6), which means that both results are below the $95 \%$ statistical reliability allowed.

On the other hand, in relation to the correctness's of exercise2 there are statistically significant changes between the pre and posttest of G1 with a significance level of 0.01 , ( $p \leq 0.05)$ which indicates that the level of reliability of the test exercise meets the statistically $95 \%$ allowed, on the contrary, the G0 present a significance level of 0.39 , ( $p \leq 0.05)$ which indicates the absence of statistically significant results and a level of reliability less than $95 \%$ statistically tolerated (See table 6).

The successes of the exercise 3 of the technical-tactic test present statistically significant changes for the G1, when relating the pre and posttest, with a value of significance equal to 0.04 , ( $p \leq$ $0.05)$ which indicates that the level of reliability of the test exercise meets $95 \%$ statistically allowed, in as for the same variable measured for theG0 the results obtained indicate statistically nonsignificant values when presenting 0.09 . ( $p \leq 0.05)$ in the significance value, indicating a level of reliability below the statistically permissible 95\%. (See table 6).

\begin{tabular}{|c|c|c|c|c|c|c|c|}
\hline \multicolumn{8}{|c|}{ Test of paired samples test Téc-Tác Ac } \\
\hline \multirow{3}{*}{\multicolumn{2}{|c|}{ Media }} & \multicolumn{4}{|c|}{ Paired differences } & \multirow{3}{*}{$\mathbf{t}$} & \multirow[t]{3}{*}{ Sig. bilateral } \\
\hline & & \multirow{2}{*}{$\begin{array}{c}\text { Standard } \\
\text { error mean }\end{array}$} & \multicolumn{2}{|c|}{ Confidence Interval } & & & \\
\hline & & & Inferior & Superior & & & \\
\hline By 1 & Ejer1.preacG1 - Ejer1.postacG1 & $-0,50$ & 0,46 & 0,59 & 1,59 & 1,08 & 0,316 \\
\hline Par 2 & Ejer1.preacG0 - Ejer1.postacG0 & $-0,75$ & 0,75 & 1,64 & 3,14 & 1,00 & 0,39 \\
\hline Par 3 & Ejer2.preacG1 - Ejer2.postacG1 & 1,50 & 0,46 & 0,41 & 2,59 & 3,24 & 0,01 \\
\hline Par 4 & Ejer2.preacG0 - Ejer2.postacG0 & 0,75 & 0,75 & 1,64 & 3,14 & 1,00 & 0,39 \\
\hline By 5 & Ejer3.al.preacG1 - Ejer3.al.postacG1 & 1,88 & 0,18 & 0,72 & 3,57 & 2,61 & 0,03 \\
\hline Par 6 & Ejer3.al.preacG0 - Ejer3.al.postacG0 & $-1,00$ & 0,41 & 0,30 & 2,30 & 2,45 & 0,09 \\
\hline
\end{tabular}

Table 6: Comparison of means T-test successes exercises Technical-tactical test.

\section{Test in competition}

When using the inferential statistic, called the Students' T-test, to compare the means of the competitive test, the results were as follows.

When making a comparison between the pre and posttest in competition for the G1, statistically significant results are present- ed with a significance level of $0.002,(\mathrm{p} \leq 0.05)$ which indicates a reliability that meets the $95 \%$ statistically allowed, on the contrary, the data thrown for the G0 result in a significance level of 0.76 , (p $\leq 0.05$ ) which indicates statistically not significant changes as indicated in table 7.

\begin{tabular}{|c|c|c|c|c|c|c|c|}
\hline \multicolumn{8}{|c|}{ Testing of sample drawnup test in Competition } \\
\hline \multicolumn{2}{|r|}{ Media } & \multicolumn{4}{|c|}{ Paired differences } & \multirow{3}{*}{$\mathbf{t}$} & \multirow[t]{3}{*}{ Sig. (bilateral) } \\
\hline & & \multirow{2}{*}{$\begin{array}{c}\text { Standard } \\
\text { error mean }\end{array}$} & \multicolumn{2}{|c|}{ Confidence Interval } & & & \\
\hline & & & Inferior & Superior & & & \\
\hline By 1 & Comp.PreG1 - Comp.postG1 & 2,18 & 0,45 & 1,11 & 3,24 & 4,83 & 0,002 \\
\hline Par 2 & Comp.PreG0 - Comp.postG0 & $-0,21$ & 0,68 & 1,95 & 2,38 & 0,31 & 0,775 \\
\hline
\end{tabular}

Table 7: Comparison of T-test means in competition. 


\section{Discussion}

\section{The training plan}

The present research exercise generated as a result a statistically very significant decrease $(\mathrm{p}<0.002)$ for the $\mathrm{G} 1$, intervention group to which a specific training load was built immersed within an annual macrocycle of work, this load had a treatment for 8 weeks framed in two work mesocycles during which the athletes were subjected to problem-solving and decision-making exercises at the table simulating real situations of judge and trying not only to stimulate their tactical thinking but also to generate in them planned plays that could be used as a strategy when facing the competition. To carry out a control of the magnitude of the workload, a volume plank and another of intensity are developed both on a scale of 1 to 5 and were distributed in the logic of the simple to the complex in 8 microcycles that began stimulating small decision-making until generating in the last weeks exercises with multiple decision possibilities, until arriving at exercises with modified competences and simulation of real competences.

Within the process of tracking information, very little research was found that broadly covers aspects of methodological order and structure of training in table tennis; just Cagigal and others (2006) develop a proposal for planning and organization according to the ages of the athletes [10]. They present structures of exercises, themes, means and important methods to take into account when planning training in table tennis, however most of the tasks and burdens that arise when strengthening technical-tactical skills are too schematic and stimulate in a very marked way strategic aspects of the order without motivating the athlete to solve problems at the table and to increase the development of his tactical thinking.

Morata (2015) also carries out a descriptive study that tries to determine possible relationships between the mode of execution of the techniques and the effectiveness of this when facing the competitions in field tennis, finding statistically significant results in several of the factors measured, through this study aims to help coaches to select and develop new methods of training that address the aspects found in direct relation to the performance of athletes and the reduction of errors during competitions, the author states that "it would be convenient to integrate technical-tactical aspects whose objective is the improvement of the variability of effects and directions in background shots and services, as well as its biomechanics. The expectation is to reduce the number of unforced and forced errors and increase the chances of unbalancing the opponent or getting shots [1]. Although the study does not establish in a timely manner the types of loads that should be applied or the way in which these should be organized during a planning process (as if this academic exercise does), and that it is also not a study directly focused on table tennis, it provides information according to the results obtained during the development of this research, validating its importance by contributing to the development of the forms and loads of training that tie up aspects that for the results obtained by the author are of a high importance in racquet sports when it is intended to increase the sports performance of athletes.

As in field tennis, table tennis is a sport where a large number of errors are commented, something that is evident after having applied both the technical-tactical test and the test in competition in the subjects of the study, this particularity is generated by the high speeds which must make decisions and execute the techniques, and the reduced space in which the game is developed, which makes it practiced with a low margin of error, regarding this, Domínguez (2010), when making a characterization of field tennis, defines it as "a game of errors" and makes a broad description of it where it intends, through the bibliographic search, determine the main aspects to take into account when planning exercises based on the tactics that can help reduce the number of mistakes made by athletes in competitions [5]. The author concludes with that the loads frequently applied to athletes stimulate an automation of tactical thinking and "not much importance is given to the player or student learning to make an appropriate decision-making depending on the situation of the game". The article concludes once again that in sports such as field tennis or table tennis generate methodological alternatives and workloads aimed at improving the tactical performance of athletes and thus establish significant improvements in the reduction of unforced errors in competition is of great importance, however, the author does not propose clear inputs of a scientifically proven procedural type that contribute to generate specific training plans to improve this condition in athletes, as if this research proposal did.

This pilot investigative exercise generated a carga that was controlled by means of the technical-tactical test, the latter had statistically significant results in the improvement of the successes of exercise 2 "Fifth balls" ( $p<0.01)$ and in exercise 3 "simulation of tie to 10 points" ( $p<0.03$ ) which and methodologically were the exercises that best evaluated if the load was being assertive in terms of 
contributing to the reduction of unforced errors in competition as the central axis of the project.

\section{Unforced errors in competition}

The importance of intervening unforced errors in competition has directed the research of several authors Urra (2014) in a study that tries to determine the efficiency of coping strategies for precompetitive anxiety in Spanish table tennis athletes finding statistically significant data in the methods of "Autodialogos" and "diaphragmatic breathing" and with it an improvement in the competitive performance of athletes and a reduction in the number of errors in matches [6], in the same way Marí (2003) proposes a psychological training program for table tennis players, finding statistically significant results in reducing the number of unforced errors in competition in athletes after applying psychological tools such as positive dialogues, the taking of micro-times in the middle of the sets, visualizations and psychological activations, among others, this psychological training plan was applied to8 table tennis players between 14 and 17 years of age [13]. However, although the results obtained by these authors in their research speak of the close relationship that unforced errors have with the competitive performance of table tennis players, these were applied by professionals of psychology; and while they can contribute in some way aspects to be taken into account in the planning and preparation of tennis players, do not constitute an input that any professional in the area of sports training can apply from their work, so, research studies such as the one developed in this pilot project, with results on the reduction of very significant unforced errors $(p<0,002)$, gain an important weight in the area.

But not only experimental research, but also various descriptive and argumentative research have been concerned about the influence that unforced errors have on performance in table tennis, López (2009) presents an exhaustive bibliographical tour and makes a judicious description of all the characteristics that make table tennis a sport with "potentially destabilizing situations" and how these generate psychological imbalances in athletes that end up resulting in error [4]; the author brings up the skills that table tennis players must develop as a profile to raise their competitive performance. Also Silveira (2013) tries to argue through various authors how athletes and students of physical education are often afraid of making mistakes and this leads them to make unforced errors, reduce their performance and even lose interest in the practice of sport [16]. These investigations acquired at the time a great theoretical support and served as a guide for the development of this research, in addition their findings try to generate that professionals in training focus their gaze on alternative ways of performing their work and generate loads to their athletes that meet needs outside of biomechanics and technical perfection, as was the focus of this research.

For his part, Abad (2008) describes a proposal for the training of table tennis from school, in which this sport can be used as a means to develop in students greater capacity for problem solving, analysis and coping with stressful situations, states that "There is a need to use a methodology for teaching table tennis that combines instruction focused on technique and that which focuses on tactics" [12]. What was constituted as one of the central axes of this research, because despite the fact that the author does not speak in a broad way about exercises or ways of structuring and planning that give priority to the development of tactic thinking, this pilot project wanted to transcend the idea and risk launching an alternative proposal of workloads for the training of table tennis players, trying to contribute to the methodological development in a clear way, of easy competition for the coaches and with a pertinent scientific basis and according to the subject matter, finding statistically significant results on the unforced errors in competition.

\section{Conclusion}

This research project aimed to quantify, observe the evolution and determine the possible changes that could arise on the unforced errors in competition in table tennis players after the application of an 8-year training plan structured in technical-tactical exercises focused on the resolution of real problems of game at the table and the stimulation of tactical thinking of athletes.

After the intervention described in detail in paragraph 3 (Methodology) has been completed and the statistical results presented in paragraph 4 (Results) have been obtained, the following conclusions can be drawn:

- The plan de training structured in technical-tactical exercises contained in this research exercise generated statistically significant changes on the unforced errors in competition in the study participants who were part of the experimental group (G1), so the null hypothesis 1 of research (Ho1) is discarded and the alternative hypothesis 1 of investigation (HA1) is approved. 
- $\quad$ Table tennis is a sport where a large number of unforced errors are made and directly influence the sports performance of athletes. Raising the levels of development of tactical thinking, improving the ability to solving problems at the table and stimulating strategic tools frequently during the development of the training process, generates a significant decrease in unforced errors and therefore an increase in the sports performance of tennis players.

- $\quad$ Some of the methods and means of training table tennis, which are often extremely analytical and focus on technical volume, must be rethought; leaving aside the staging of real game actions and the ability to use techniques as a tool to solve tactical problems at the table.

- The technical-tactical test proposed as a pilot test to measure the relevance of the training load generated, presented statistically significant improvements in two of its exercises that were the ones that best simulated real game situations and forced the athletes to make more efficient tactical decisions, which accounts for a good management of the loads; and it is also directly proportional to the results obtained in the test in competition. However, the exercise that did not have statistically significant improvements (third balls), tried to measure the efficiency of the load generated in terms of the strategic approaches of the tennis players evaluated, which was not one of the most determining axes of the research, but also presented slight positive variations and is a point to take into account as a tool for improvement in the reduction of unforced errors in competition.

\section{Bibliography}

1. Morata A. "Analysis of the technical-tactical patterns and the intensity of the effort in tennis players of child category". Faculty of Health and Sports Sciences, Huesca, Zaragoza, Spain (2015).

2. Daneri F. "Behavioral biology: Psychobiology of the Stress". Faculty of Psychology, University of Buenos Aires, Argentina (2012).

3. Minisalud. "Clinical Practice Guide for the Management of Patients with Anxiety Disorder in Primary Care". Ministry of Health and Consumer Affairs. Madrid, Spain (2007).
4. Lopez J. "Psychological Skills to Improve Performance in Table Tennis. Notebook of Sports Psychology". Faculty of Psychology, University of Murcia, Spain 9 (2009): 53-72.

5. Dominguez G. "Aspects to take into account para the design of exercises based on tactics in the sport of tennis". Trances 2.5 (2010): 423-440.

6. Urra B. "Evaluation of the effectiveness of the training of coping strategies in the level of precompetitive anxiety in tennis players". Review of Sport Psychology 23 (2014): 67-74.

7. Lopategui E. "Determination of Body Mass Index: Laboratory Experiment I-23". Laboratory Experiments in Exercise Physiology. Puerto Rico (2008).

8. Bermejo J. "Review of the Concept of Sports Technique from the Perspective Biomechanics of movement". Digital Journal of Physical Education 25 (2013).

9. Godoy D., et al. "Level of mastery of psychological skills in Young table tennis, badminton and football players". Revista de Psicología del Deporte 18 (2009): 7-22.

10. Cagigal 0 and others. "Sportsman: Table Tennis". National Table Tennis Commission. Cuba (2006).

11. Urra B. "Memories international scientific congress applied to table tennis: Characterization Psychological table tennis and influence on the communicative work of the coach". Santiago, Chile (2003).

12. Abad M. "Proposal for The Teaching of Table Tennis in Primary and Secondary Education". Retos Magazine: New trends in Education, Physical Sport and Recreation 13 (2008): 33-38.

13. Marí J. "Psychological Training Program for Player is High Level Table Tennis". Journal of Sports Psychology 6 (2003).

14. Poveda J. "Theoretical Foundations and Practical Application of Decision Making in Sport". E-BM: Journal of Sports Sciences 6 (2010): 101-110.

15. Chóliz M. "Psychology of emotion: The Emotional Process". Department of Basic Psychology: University of Valencia, Spain (2005).

16. Silveira. "Fear of Making Mistakes in Physical Education and Sport”. Dissertation. ELCHE: Miguel Hernández University, Alicante, Spain (2013). 
17. Moreno J and others. "Relationship of the climate task of equals with the fear of making mistakes in sport: Differences by sex in a sample of basketball players". ELCHE: Miguel Hernández University, Alicante, Spain (2010).

18. Cano 0. "Models of Planning and their Applicability in the Preparation of Professional Football Teams That Participate in the Colombian Tournament Category Primera A". Monograph to Aspire to the Title of Specialist. University of Antioquia, University Institute of Physical Education. Medellin, Colombia (2010).

19. Vélez G. "The Implementation of a Traditional Training Plan for the Improvement of the 400 Meter Freestyle Event of the Swimmers Next to Attend central American and National Interclubes Games in the Modality of Swimming Races". VIREF. University of Antioquia, University Institute of Physical Education. Medellin, Colombia (2007).

20. Matveiev L. "Periodization of Sports Training". National Institute of Physical Education of Madrid, Spain (1997).

21. Fields J and Cevera V. "Theory and Planning of Sports Training". Second Edition. Editorial Paidotribo, Spain (2003).

22. Hoary J. "Effects of a Structured Training Plan Through The Intensive Continuous Method on Vo2 Maximum and Lat Displacement Speed in Antioquia Canoeists". University of Antioquia: I.U.E.F. Medellín: Colombia (2013).

23. Molodzoff P. “Advanced Training Manual”. International Table Tennis Federation. Lausanne, Switzerland (2008).

Volume 4 Issue 10 October 2021

(C) All rights are reserved by Juan Camilo Soto Jaramillo. 